\title{
Editorial: The Emory-Tibet Science Initiative: A Historic Collaboration Between Modern Science and Tibetan Buddhism - Insights From a Spiritual Leader
}

\author{
Robin Nusslock ${ }^{1}$, Meena M. Balgopal ${ }^{2}$, Gillian Hue ${ }^{3}$, Joel Zivot $^{4}$, Lobsang Tenzin Negi ${ }^{5}$ and \\ Arri Eisen ${ }^{6 *}$ \\ ${ }^{1}$ Department of Psychology, Northwestern University, Evanston, IL, United States, ${ }^{2}$ Department of Biology, Colorado State \\ University, Fort Collins, CO, United States, ${ }^{3}$ Neuroscience and Behavioral Biology, Emory University, Atlanta, GA, United States, \\ ${ }^{4}$ Department of Anesthesiology, Emory University, Atlanta, GA, United States, ${ }^{5}$ Department of Religion, Emory University, Atlanta, \\ GA, United States, ${ }^{6}$ Department of Biology, Emory University, Atlanta, GA, United States
}

Keywords: cross-cultural education, science education, Dalai Lama, science and ethics, communicating science

Editorial on the Research Topic

The Emory-Tibet Science Initiative: A Historic Collaboration Between Modern Science and Tibetan Buddhism-Insights From a Spiritual Leader

\section{OPEN ACCESS}

Edited and reviewed by:

José Castro-Sotomayor. California State University, Channel Islands, United States

*Correspondence: Arri Eisen aeisen@emory.edu

Specialty section: This article was submitted to Science and Environmental Communication,

a section of the journal

Frontiers in Communication

Received: 13 September 2021 Accepted: 30 September 2021 Published: 14 October 2021

Citation: Nusslock R, Balgopal MM, Hue G, Zivot J, Negi LT and Eisen A (2021) Editorial: The Emory-Tibet Science Initiative: A Historic Collaboration Between Modern Science and Tibetan

Buddhism-Insights From a Spiritual Leader.

Front. Commun. 6:765368. doi: $10.3389 /$ fcomm.2021.765368
Today, any Tibetan Buddhist monastic who is considering earning the highest academic degree in his or her institution must complete a 6-year curriculum in physics, neuroscience, and biology. Why? Why would an ancient religion that originated and evolved in the Global South invite modern scientists from the Global North into its monastic universities to teach and integrate science into the curriculum: expand, and contextualize the curriculum rather than narrow it as has occurred with most advanced degrees in the US?

The Emory-Tibet Science Initiative (ETSI), our project teaching modern science to Buddhist monastics, emerges from the Dalai Lama's years-long engagement with scientists to discuss how to effectively integrate scientific knowledge and the knowledge of Indo-Tibetan traditions to best serve humanity. The spiritual leader of Tibetan Buddhism represents the centuries-old Nalanda tradition, a worldview grounded in the idea that in order to understand your own worldview, you must understand everyone else's. Thus, the Dalai Lama's invitation to scientists in 2008 to catalyze the first major renovation of his monastics' curriculum in 600 years was a major step toward integrating scientific and traditional knowledges.

The Dalai Lama always had a curiosity and reverence for science. As a child, he used a telescope that belonged to his predecessor to peer into the night sky in the high altitude of Tibet, which offers one of the most spectacular views of the stars. He has a lifelong hobby of dismantling and reassembling mechanical objects, mastering such processes well enough to become a repairer of watches in his childhood Tibet. He came, in time, to recognize the technology he found so interesting was the fruit, or expression, of a scientific approach to investigating the world.

Over the years, the Dalai Lama became fascinated with this approach and began to notice similarities in the spirit of inquiry between science and Buddhist thought. He saw science first and foremost as a mode of inquiry that gives detailed knowledge of the world and the underlying laws of nature, which we infer from empirical data. Science proceeds by means of a very specific method that involves measurement, quantification, and verification through repeated experiments. Buddhism has a similar investigative spirit. Although Buddhism has come to evolve as a religion with a 
characteristic body of scriptures and rituals, Buddhist scriptural authority cannot outweigh an understanding based on reason and experience. In fact, the Buddha himself famously undermines the scriptural authority of his own words when he asks his followers not to accept the validity of his teachings simply on the basis of reverence for him, but to test the truth of what he said through reasoned examination and experience. So, one fundamental attitude shared by Buddhism and science is a commitment to the continual investigation of reality by empirical means and a willingness to discard accepted or long-held positions if investigations suggest that the truth is different.

The Dalai Lama resonates with many scientific discoveries and ideas. He is especially struck by Darwin's theory of evolution, by the tenets of quantum physics, and by the contributions of science to our quality of life and life expectancy. He points out, though, that without an ethical framework, the discoveries of science can be mis-used and cause great harm. An ethical imperative is especially relevant today, given advancements in synthetic biology that soon may allow scientists to edit the human genome and alter the evolutionary future of humanity. Like any instrument, science can be put to good use or bad. It is the state of mind of the person wielding the instrument that determines to what end it will be put.

In Buddhism, the highest spiritual ideal is compassion, and the Dalai Lama strongly encourages science during the 21 st century be guided by this north star of compassion, and a commitment to enhance the welfare and well-being of all sentient beings. He believes that science would benefit from a "secular ethics," that is, an ethics that does not rely on any particular belief system, but one that can be embraced and practiced by both those who follow a particular faith tradition and those who do not. The goal of such ethics is to ensure that science never becomes divorced from the basic human feelings of empathy, connection, and compassion with our fellow beings.

Although science and Buddhism share a commitment to an empirical mindset, they frequently differ in their methods. Science typically uses instruments, quantitative methods and third-person perspectives to examine external phenomena. Buddhism, by contrast, understands the importance of firstperson observation and the development of refined attention to directly observe both inner and outer states-mind and body, and their interactions with the external world. The challenges of today's world suggest we are at a point in history where these two traditions can, and should, start working together, communicating across the boundaries of religion, science, values, and culture.

The Dalai Lama invited scientists into monastic universities to help facilitate this collaborative relationship. The ultimate goal of ETSI is to build bridges between two complementary systems of knowledge by educating Tibetan monastics in science, so they can become potential collaborators in the science of mind and body. ETSI is designed to give Tibetan monastics new tools for understanding the world, while also providing them with fresh perspectives on how to employ and adapt time-tested, Buddhist, contemplative methodologies for the relief of suffering in the contemporary world.

This is a monumental exercise at the frontiers of $21 \mathrm{st}$ century communication. But this unprecedented opportunity for transformation also presents challenges and demands critical consideration. While the Dalai Lama requests that the scientists "just teach the science" to the monks and nuns, inevitably students and teachers ponder, question, and debate the overlaps, similarities, and disconnects between science and Buddhism-both because they are striking, and because good teachers always draw on their students' preexisting knowledge and experience. A great challenge of ETSI, and of any meaningful cross-cultural interaction, is effective communication. Effective communication of the deepest kind requires a recognition and integration of basic human values-kindness, compassion, forgiveness, and generosity. Tibetan Buddhism holds these values as necessary for the flourishing of human society. This special issue of Frontiers in Communication is rich with data from participants in ETSI-scientists, monastics, and lay Tibetan translators - that illustrate how these basic human values, so central to Tibetan Buddhism, transform their thinking about science and religion and about communication, both within the project and, perhaps even more powerfully, back in the participants' "home" institutions-the centers of monastic studies and the "western" science labs and classrooms.

The Buddha is credited with saying, "when the student is ready, the teacher will appear." Through ETSI, the student has become the teacher, and vice versa. And what has emerged is a rich and historic conversation between academic science and Indo-Tibetan traditions that we hope can help us better address the problems of humanity and make the world a more compassionate place.

\section{AUTHOR CONTRIBUTIONS}

$\mathrm{RN}$ wrote a first draft, $\mathrm{AE}$ shaped it into a second draft, and all the other authors contributed comments and rewrites.

Conflict of Interest: The authors declare that the research was conducted in the absence of any commercial or financial relationships that could be construed as a potential conflict of interest.

Publisher's Note: All claims expressed in this article are solely those of the authors and do not necessarily represent those of their affiliated organizations, or those of the publisher, the editors and the reviewers. Any product that may be evaluated in this article, or claim that may be made by its manufacturer, is not guaranteed or endorsed by the publisher.

Copyright (c) 2021 Nusslock, Balgopal, Hue, Zivot, Negi and Eisen. This is an openaccess article distributed under the terms of the Creative Commons Attribution License (CC BY). The use, distribution or reproduction in other forums is permitted, provided the original author(s) and the copyright owner(s) are credited and that the original publication in this journal is cited, in accordance with accepted academic practice. No use, distribution or reproduction is permitted which does not comply with these terms. 